Provided for non-commercial research and education use. Not for reproduction, distribution or commercial use.

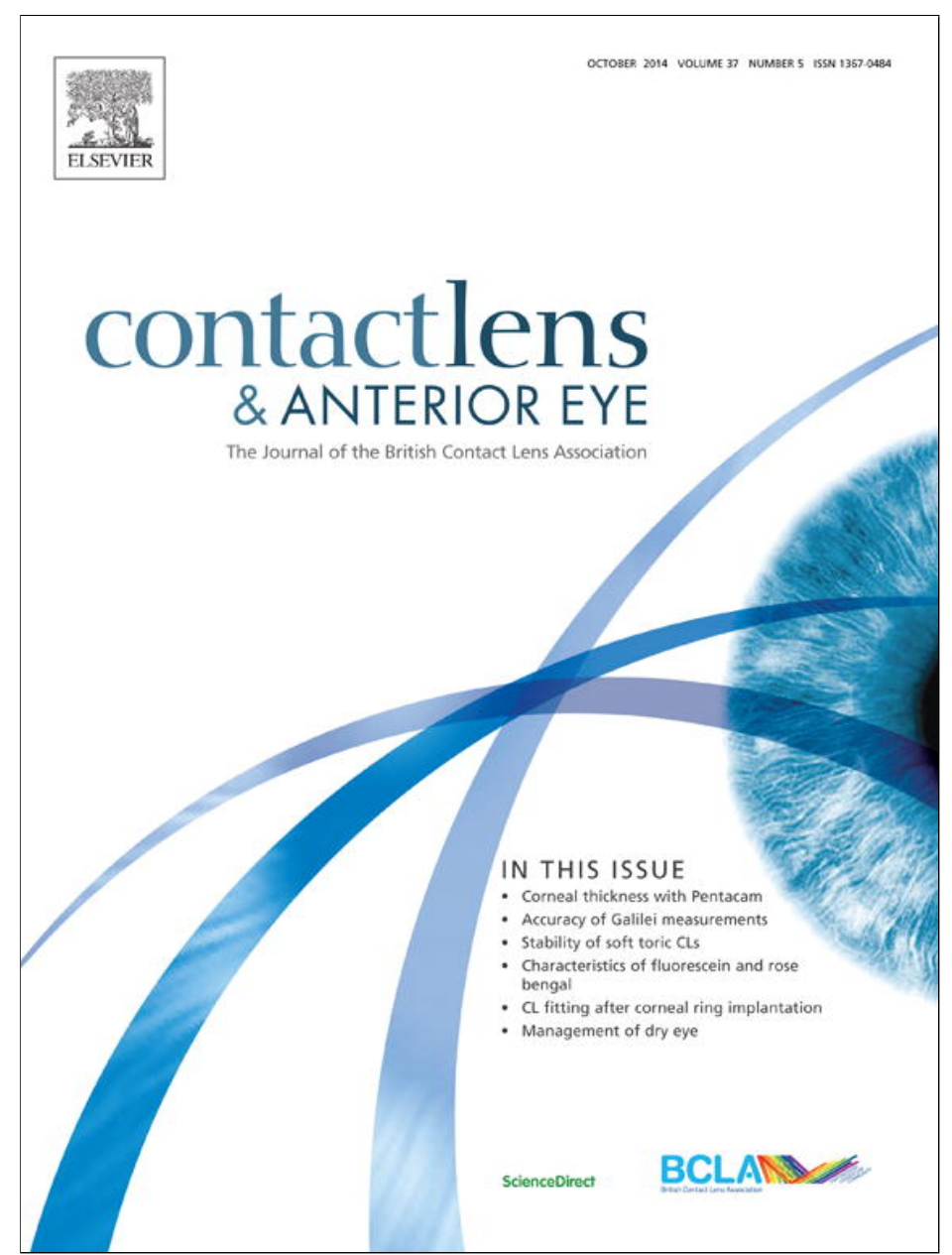

This article appeared in a journal published by Elsevier. The attached copy is furnished to the author for internal non-commercial research and education use, including for instruction at the authors institution and sharing with colleagues.

Other uses, including reproduction and distribution, or selling or licensing copies, or posting to personal, institutional or third party websites are prohibited.

In most cases authors are permitted to post their version of the article (e.g. in Word or Tex form) to their personal website or institutional repository. Authors requiring further information regarding Elsevier's archiving and manuscript policies are encouraged to visit:

http://www.elsevier.com/authorsrights 


\title{
Examination of ocular biomechanics with a new Scheimpflug technology after corneal refractive surgery
}

\author{
Ziad Hassan ${ }^{\mathrm{a}}$, Laszlo Modis Jr. ${ }^{\mathrm{b}}$, Eszter Szalai ${ }^{\mathrm{b}}$, Andras Berta ${ }^{\mathrm{b}}$, Gabor Nemeth ${ }^{\mathrm{b}, *}$ \\ a Orbi-Dent Health and Laser Center, Debrecen, Hungary \\ ${ }^{\mathrm{b}}$ Department of Ophthalmology, Medical and Health Science Center, University of Debrecen, Debrecen, Hungary
}

\section{A R T I C L E I N F O}

\section{Article history:}

Received 27 November 2013

Received in revised form 27 March 2014

Accepted 1 May 2014

\section{Keywords:}

Ocular biomechanics

CorVis ST

LASIK

PRK

Scheimpflug technology

\begin{abstract}
A B S T R A C T
Purpose: To analyze the early results of a new device measuring ocular biomechanics after corneal refractive surgery.

Patients and methods: Thirty nine refractive surgery patients were enrolled in the study (age: $32.6 \pm 9.9$ years). Laser in situ keratomileusis (LASIK) was performed on 52 eyes of 26 patients and photorefractive keratectomy (PRK) was done on 26 eyes of 13 patients. Ten device-specific biomechanical parameters, intraocular pressure (IOP) and pachymetry were measured preoperatively and at day 1 , week 1 and month 1 after the surgeries with a new technology based on Scheimpflug imaging (CorVis ST, Oculus). Results: In case of LASIK, the day after the procedure, radius values showed significant differences compared to preoperative data. One month after surgery, radius values, velocity of the second applanation and pachymetry showed significant differences compared to preoperative data. In case of PRK, the day after the procedure, significant differences in IOP, maximum amplitude at the apex, A1 time, A2 velocity and highest concavity time were measured. After 1 month of PRK, there were no differences in the parameters compared to preoperative data except pachymetry.

Conclusions: We observed that some specific biomechanical parameters changed measured with CorVis ST after LASIK and PRK, in the early postoperative time. However, most of these parameters remain unchanged after one month of LASIK and PRK compared to preoperative data.
\end{abstract}

(c) 2014 British Contact Lens Association. Published by Elsevier Ltd. All rights reserved.

\section{Introduction}

The ophthalmological diagnostic techniques currently used in common practice only have the potential to measure the static parameters of the anterior segment of the eye; despite the cornea being a tissue with viscous and elastic properties [1]. Until recently, the only device which conducted in vivo measurements of the ocular biomechanical properties was the Ocular Response Analyzer (ORA, Reichert Ophthalmic Instruments, Depew, New York, USA), which has been available since 2005 [2,3].

With ORA, the biomechanical properties of the cornea can be measured, which can help us the diagnosis of glaucoma and in the assessment of the outcomes of different refractive surgeries [4-8]. The first publication about results with ORA has already reported significant differences in the biomechanical parameters between

\footnotetext{
* Corresponding author at: Department of Ophthalmology, University of Debrecen, Nagyerdei Boulevard 98, H-4012 Debrecen, Hungary. Tel.: +36 52255456; fax: +36 52255626.

E-mail address: nemeth222@yahoo.com (G. Nemeth).
}

healthy and keratoconus eyes and in those subsequent to refractive surgeries [9].

Recently, a new device has been made available for measuring ocular biomechanical properties. The CorVis ST (Corneal Visualization Scheimpflug Technology, Oculus Inc., Wetzlar, Germany) uses ultra high-speed Scheimpflug photography and an air impulse to measure the specific parameters of the cornea. Our aim was to evaluate early ocular biomechanical changes after laser in situ keratomileusis (LASIK) and photorefractive keratectomy (PRK) with this new technology.

\section{Patients and methods}

\subsection{Patients}

Thirty nine corneal refractive surgery candidates were enrolled in this study. All subjects had no history or signs of previous or present systemic and ocular disorder other than refractive errors. A complete ophthalmological examination was performed on each subject preoperatively. The research protocol adhered to the tenets 
of the Declaration of Helsinki and detailed informed consent was signed by all patients.

\subsection{LASIK procedure}

LASIK surgery was performed using an InPro Gauss excimer laser device (InPro Intraokulare Prothetik GmbH, Norderstedt, Germany) and a Zyoptix XP microkeratome (Bausch\&Lomb Inc., Rochester, New York, USA). Before the operation, topical anaesthetic eye drops (tetracaine hydrochloride) were instilled three times over a five-minute interval. An anterior corneal flap was created, with a diameter of $9.5 \mathrm{~mm}$ and a thickness of $120 \mu \mathrm{m}$. Postoperatively, patients received tobramycine and dexamethasone eye drops five times a day for two weeks. Preservative-free artificial tears (Refresh Classic, Allergan) were also administered five times a day from days 1 to 60 .

\subsection{PRK procedure}

Topical anaesthetic (tetracaine hydrochloride) eye drops were administered at least twice before the surgery. De-epithelization was performed with a blunt keratome blade knife after epithelial marking at $7.0-7.5 \mathrm{~mm}$. The epithelium was scraped gently from the periphery to the centre. Residual epithelial debris was removed with a sterile microsponge. The PRK was performed using an InPro Gauss excimer laser device (InPro Intraokulare Prothetik $\mathrm{GmbH}$, Norderstedt, Germany). Postoperative treatment consisted of pain killers (diclofenac) during the first and the second day, antibiotic (tobramycine) drops or ointment and a patch until the epithelium was healed. Topical corticosteroid eye drops (dexamethasone) were used five times daily in the first month, four times daily in the second month and three times daily in the third month.

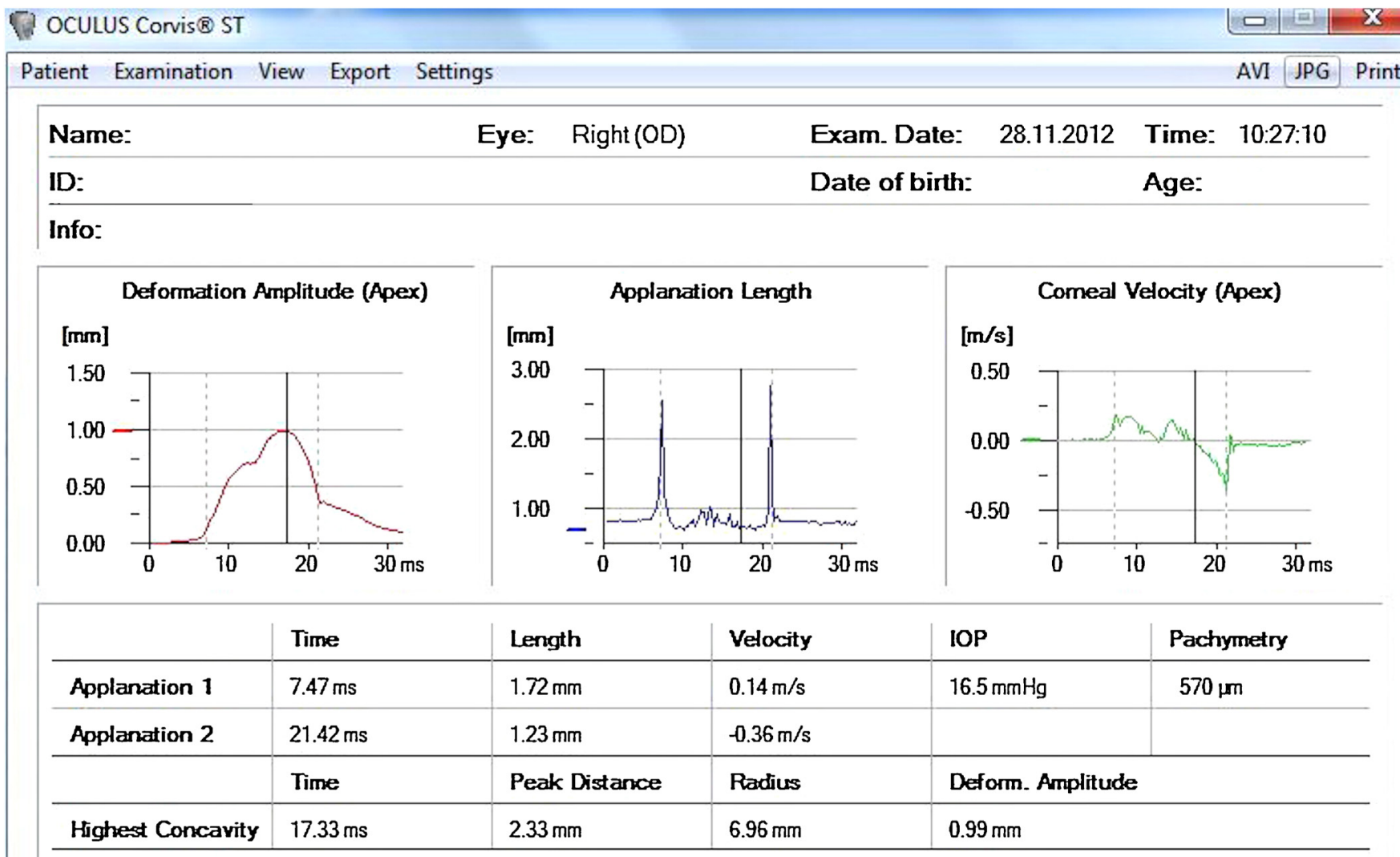

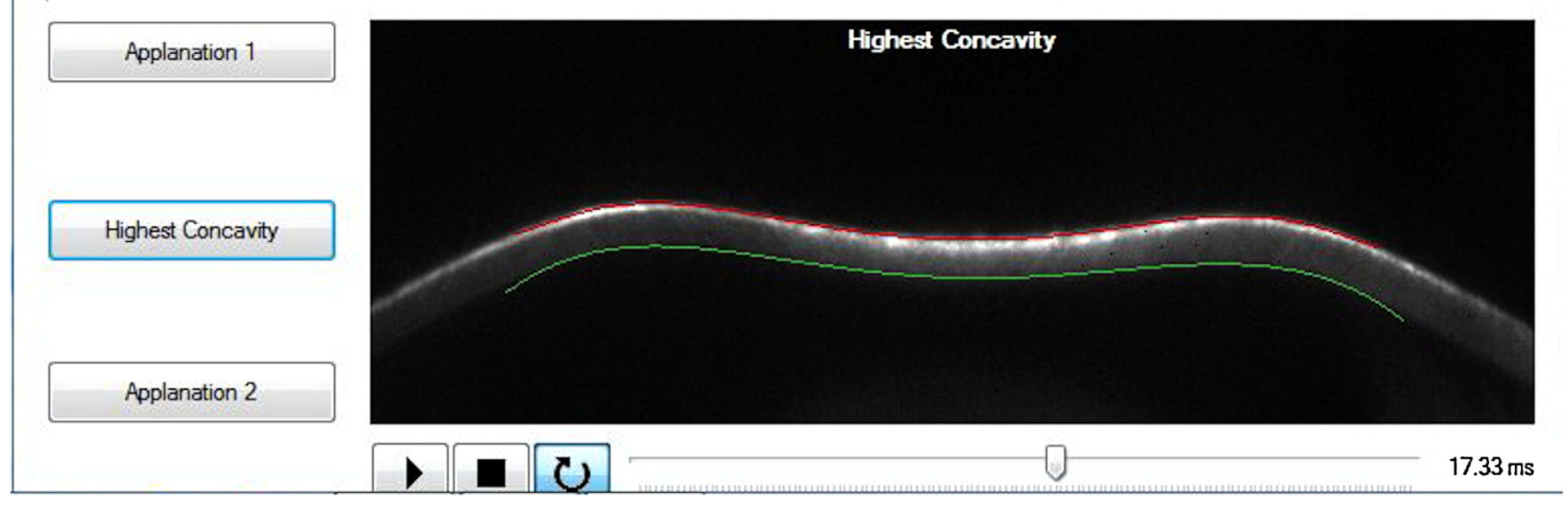

Fig. 1. Demonstrative picture obtained with CorVis ST at the highest concavity time. The device measures the maximum deformation amplitude of the cornea, time taken to reach it, first and second applanation times, applanation lengths, two corneal speed values, peak distance and a radius value at the time of the highest concavity. 
In all cases, preoperatively and at day 1 , week 1 and month 1 postoperatively, at nearly the same time of day, ocular biomechanical parameters were obtained using CorVis ST (software version 1.00r24 rev. 772) by the same investigator in every case. CorVis ST is a non-contact tonometer and pachymeter which measures ten device-specific ocular biomechanical parameters. The device uses an ultra high-speed Scheimpflug camera (4330 frames/s) covering $8.0 \mathrm{~mm}$ horizontally. The light source is an UV free blue LED light with a wavelength of $455 \mathrm{~nm}$. In the slow motion video, the deformation response of the cornea to a high intensity air impulse is seen approximately within a range of $30 \mathrm{~ms}$. The video and the data obtained during the measurements are exported from the device for further statistical analysis. Due to the air impulse, the cornea goes through three phases (first applanation, highest concavity and second applanation). During these phases a number of parameters are recorded: maximum deformation amplitude, which is the highest concavity $(\mathrm{HC})$ of the centre of the cornea in millimetres; time taken to reach it (HC time) from the air pulse starts; first and second applanation time (A1 and A2 time); cord lengths of the applanations, which are the lengths of the flattened cornea in millimetres at the moment of $\mathrm{A} 1$ and $\mathrm{A} 2$; maximum corneal velocity during the first and second applanation phase (A1 and $A 2$ velocity); peak distance, which is the distance of the two apexes ('knees') at the moment of the highest concavity and a radius value which represents the central concave curvature at HC. An illustrating snapshot obtained with CorVis ST with specific data can be seen in Fig. 1. Central corneal thickness is also determined. Once these data are obtained, the equipment calculates the intraocular pressure (IOP).

The examined patient is seated with their chin on the chinrest and forehead against the equipment. Using the joystick, the examiner targets the centre of the cornea, thus enabling the patient to see a red light on which they should fix their gaze. The adjusting direction we need to be able to focus on the corneal apex is seen on the display of the device. At an accurate setting, the air puff automatically starts. After the measurements, the data are exported to the attached computer.
Statistical analysis was performed with MedCalc 10.0 software. Descriptive statistical results were described as mean, standard deviation (SD) and 95\% confidence interval (95\% CI) for the mean. The difference between the data groups was described by Student's paired $t$-test. $p$ value below 0.05 was considered statistically significant.

\section{Results}

Examinations were performed on 78 eyes of 39 refractive surgery patients (age: $32.6 \pm 9.9$ years). A summary of the data measured by CorVis ST is presented in Tables 1 and 2. Regarding preoperative data, we found significant difference between LASIK and PRK group only in the case of radius value $(p=0.02)$.

LASIK was performed on 52 eyes of 26 patients $(33.48 \pm 10.04$ years). The manifest refraction spherical equivalent was $-4.7 \pm 4.8 \mathrm{D}$ (range: $-12.0 \mathrm{D}$ myopia to $+3.0 \mathrm{D}$ hyperopia). The day after the procedure, radius values showed significant difference compared to the preoperative data. One month after surgery, radius values, velocity of the second applanation and pachymetric values showed statistical significant difference compared to preoperative data (Table 1 ).

PRK was carried out on 26 eyes of 13 patients (age: $30.52 \pm 9.31$ years). The manifest refraction spherical equivalent was $-1.02 \pm 3.89$ (range: $-8.5 \mathrm{D}$ myopia to $+6.0 \mathrm{D}$ hyperopia). The day after the procedure, we observed significant differences in the following parameters: intraocular pressure, maximum amplitude at the apex, A1 time, A2 velocity and HC time. One month after surgery, there were no differences in specific parameters compared to preoperative data except in pachymetry (Table 2).

Correlations between changes in biomechanical parameters and the spherical equivalent of correction during surgery were as follows: In the case of LASIK, changes in IOP, pachymetry, A1 time, $A 1$ velocity, A2 length and radius values showed significant correlations with the magnitude of the corrected refraction error. In the case of PRK, changes in pachymetric data and radius value

Table 1

Data obtained by CorVis ST in LASIK patients.

\begin{tabular}{|c|c|c|c|c|c|c|c|}
\hline & Preoperative & Day 1 & $p$ & Day 7 & $p$ & Day 30 & $p$ \\
\hline IOP [mmHg] & $\begin{array}{l}15.29 \pm 2.95 \\
(14.47-16.12)\end{array}$ & $\begin{array}{l}13.95 \pm 4.69 \\
(12.64-15.26)\end{array}$ & 0.08 & $\begin{array}{l}15.68 \pm 6.37 \\
(13.91-17.45)\end{array}$ & 0.7 & $\begin{array}{l}14.19 \pm 4.15 \\
(13.08-15.31)\end{array}$ & 0.11 \\
\hline Pachy $[\mu \mathrm{m}]$ & $\begin{array}{l}547.18 \pm 44.91 \\
(534.51-559.77)\end{array}$ & $\begin{array}{l}526.17 \pm 61.52 \\
(509.04-543.30)\end{array}$ & 0.05 & $\begin{array}{l}526.69 \pm 62.17 \\
(509.38-544.00)\end{array}$ & 0.06 & $\begin{array}{l}524.00 \pm 63.21 \\
(506.74-541.25)\end{array}$ & $0.03^{*}$ \\
\hline Def. amp. $\max [\mathrm{mm}]$ & $\begin{array}{l}1.06 \pm 0.11 \\
(1.03-1.09)\end{array}$ & $\begin{array}{l}1.08 \pm 0.12 \\
(1.05-1.12)\end{array}$ & 0.27 & $\begin{array}{l}1.02 \pm 0.17 \\
(0.98-1.07)\end{array}$ & 0.21 & $\begin{array}{l}1.08 \pm 0.14 \\
(1.04-1.12)\end{array}$ & 0.36 \\
\hline A1 time [ms] & $\begin{array}{l}7.32 \pm 0.33 \\
(7.23-7.42)\end{array}$ & $\begin{array}{l}7.18 \pm 0.50 \\
(7.04-7.32)\end{array}$ & 0.08 & $\begin{array}{l}7.37 \pm 0.69 \\
(7.17-7.56)\end{array}$ & 0.69 & $\begin{array}{l}7.22 \pm 0.44 \\
(7.10-7.34)\end{array}$ & 0.19 \\
\hline A1 length [mm] & $\begin{array}{l}1.73 \pm 0.31 \\
(1.65-1.82)\end{array}$ & $\begin{array}{l}1.74 \pm 0.27 \\
(1.67-1.82)\end{array}$ & 0.88 & $\begin{array}{l}1.77 \pm 0.31 \\
(1.68-1.86)\end{array}$ & 0.53 & $\begin{array}{l}1.78 \pm 0.31 \\
(1.70-1.86)\end{array}$ & 0.41 \\
\hline A1 velocity $[\mathrm{m} / \mathrm{s}]$ & $\begin{array}{l}0.15 \pm 0.03 \\
(0.19-0.16)\end{array}$ & $\begin{array}{l}0.14 \pm 0.03 \\
(0.13-0.15)\end{array}$ & 0.38 & $\begin{array}{l}0.14 \pm 0.04 \\
(0.13-0.15)\end{array}$ & 0.48 & $\begin{array}{l}0.15 \pm 0.04 \\
(0.13-0.16)\end{array}$ & 0.81 \\
\hline A2 time [ms] & $\begin{array}{l}21.52 \pm 0.81 \\
(21.29-21.74)\end{array}$ & $\begin{array}{l}21.63 \pm 0.66 \\
(21.45-21.82)\end{array}$ & 0.42 & $\begin{array}{l}21.54 \pm 0.58 \\
(21.38-21.71)\end{array}$ & 0.84 & $\begin{array}{l}21.71 \pm 0.48 \\
(21.58-21.84)\end{array}$ & 0.13 \\
\hline $\mathrm{A} 2$ length [mm] & $\begin{array}{l}1.77 \pm 0.47 \\
(1.64-1.91)\end{array}$ & $\begin{array}{l}1.70 \pm 0.45 \\
(1.57-1.83)\end{array}$ & 0.41 & $\begin{array}{l}1.70 \pm 0.51 \\
(1.56-1.84)\end{array}$ & 0.45 & $\begin{array}{l}1.82 \pm 0.55 \\
(1.67-1.96)\end{array}$ & 0.66 \\
\hline A2 velocity $[\mathrm{m} / \mathrm{s}]$ & $\begin{array}{l}-0.38 \pm 0.07 \\
(-0.40 \text { to } \\
-0.36)\end{array}$ & $\begin{array}{l}-0.42 \pm 0.15 \\
(-0.46 \text { to } \\
-0.38)\end{array}$ & 0.12 & $\begin{array}{l}-0.39 \pm 0.11 \\
(-0.42 \text { to } \\
-0.36)\end{array}$ & 0.66 & $\begin{array}{l}-0.43 \pm 0.12 \\
(-0.46 \text { to } \\
-0.39)\end{array}$ & $0.03^{*}$ \\
\hline HC Time [ms] & $\begin{array}{l}16.55 \pm 0.46 \\
(16.42-16.68)\end{array}$ & $\begin{array}{l}16.66 \pm 0.52 \\
(16.51-16.80)\end{array}$ & 0.27 & $\begin{array}{l}16.62 \pm 0.34 \\
(16.53-16.71)\end{array}$ & 0.37 & $\begin{array}{l}16.61 \pm 0.35 \\
(16.51-16.70)\end{array}$ & 0.45 \\
\hline Peak dist. [mm] & $\begin{array}{l}3.39 \pm 1.22 \\
(3.05-3.73)\end{array}$ & $\begin{array}{l}3.57 \pm 1.34 \\
(3.19-3.94)\end{array}$ & 0.49 & $\begin{array}{l}3.58 \pm 1.25 \\
(3.24-3.93)\end{array}$ & 0.43 & $\begin{array}{l}3.77 \pm 1.25 \\
(3.44-4.11)\end{array}$ & 0.11 \\
\hline Radius [mm] & $\begin{array}{l}7.69 \pm 1.16 \\
(7.37-8.02)\end{array}$ & $\begin{array}{l}7.10 \pm 1.37 \\
(6.72-7.48)\end{array}$ & $0.01^{*}$ & $\begin{array}{l}7.20 \pm 1.30 \\
(6.84-7.56)\end{array}$ & $0.04^{*}$ & $\begin{array}{l}7.11 \pm 1.05 \\
(6.83-7.39)\end{array}$ & $<0.01^{*}$ \\
\hline
\end{tabular}

IOP, intraocular pressure; Pachy, central corneal thickness; Def. amp. max, maximum amplitude at the apex (highest concavity); A1 time, time from starting until the first applanation; A1 length, cord length of the first applanation; A1 velocity, speed of the first applanation; A2 time, time from starting until the second applanation; A2 length, cord length of the second applanation; A2 velocity, speed of the second applanation; HC time, time from starting until highest concavity (HC) is reached; peak dist., distance of the two apex at highest concavity; radius, central concave curvature at $\mathrm{HC}$. All data in mean $\pm \mathrm{SD}(95 \% \mathrm{CI})$. SD, standard deviation; $95 \% \mathrm{CI}$, $95 \%$ confidence interval for the mean.

Significant $p$ value compared to preoperative data. 
Table 2

Data obtained by CorVis ST in PRK patients.

\begin{tabular}{|c|c|c|c|c|c|c|c|}
\hline & Preoperative & Day 1 & $p$ & Day 7 & $p$ & Day 30 & $p$ \\
\hline IOP [mmHg] & $\begin{array}{l}15.26 \pm 4.63 \\
(13.35-17.17)\end{array}$ & $\begin{array}{l}12.13 \pm 3.22 \\
(10.71-13.56)\end{array}$ & $0.01^{*}$ & $\begin{array}{l}13.50 \pm 4.82 \\
(11.17-15.82)\end{array}$ & 0.22 & $\begin{array}{l}14.16 \pm 5.15 \\
(12.03-16.29)\end{array}$ & 0.43 \\
\hline Pachy $[\mu \mathrm{m}]$ & $\begin{array}{l}538.92 \pm 41.82 \\
(521.65-556.18)\end{array}$ & $\begin{array}{l}515.85 \pm 50.65 \\
(492.14-539.55)\end{array}$ & 0.10 & $\begin{array}{l}495.22 \pm 44.31 \\
(473.18-517.26)\end{array}$ & $<0.01^{*}$ & $\begin{array}{l}486.58 \pm 39.15 \\
(470.05-503.11)\end{array}$ & $<0.01^{*}$ \\
\hline Def. amp. max [mm] & $\begin{array}{l}1.08 \pm 0.11 \\
(1.03-1.12)\end{array}$ & $\begin{array}{l}1.15 \pm 0.13 \\
(1.09-1.21)\end{array}$ & $0.03^{*}$ & $\begin{array}{l}1.09 \pm 0.10 \\
(1.04-1.14)\end{array}$ & 0.73 & $\begin{array}{l}1.06 \pm 0.11 \\
(1.01-1.11)\end{array}$ & 0.61 \\
\hline A1 time [ms] & $\begin{array}{l}7.32 \pm 0.47 \\
(7.12-7.51)\end{array}$ & $\begin{array}{l}6.99 \pm 0.29 \\
(6.86-7.12)\end{array}$ & $<0.01^{*}$ & $\begin{array}{l}7.13 \pm 0.50 \\
(6.89-7.37)\end{array}$ & 0.20 & $\begin{array}{l}7.19 \pm 0.54 \\
(6.96-7.42)\end{array}$ & 0.38 \\
\hline A1 length [mm] & $\begin{array}{l}1.74 \pm 0.29 \\
(1.62-1.86)\end{array}$ & $\begin{array}{l}1.77 \pm 0.30 \\
(1.64-1.91)\end{array}$ & 0.71 & $\begin{array}{l}1.65 \pm 0.25 \\
(1.52-1.77)\end{array}$ & 0.25 & $\begin{array}{l}1.78 \pm 0.33 \\
(1.64-1.92)\end{array}$ & 0.66 \\
\hline A1 velocity $[\mathrm{m} / \mathrm{s}]$ & $\begin{array}{l}0.15 \pm 0.04 \\
(0.14-0.17)\end{array}$ & $\begin{array}{l}0.16 \pm 0.04 \\
(0.14-0.18)\end{array}$ & 0.46 & $\begin{array}{l}0.13 \pm 0.03 \\
(0.12-0.15)\end{array}$ & 0.10 & $\begin{array}{l}0.14 \pm 0.04 \\
(0.13-0.16)\end{array}$ & 0.48 \\
\hline A2 time [ms] & $\begin{array}{l}21.55 \pm 0.58 \\
(21.31-21.80)\end{array}$ & $\begin{array}{l}21.65 \pm 0.88 \\
(21.25-22.06)\end{array}$ & 0.65 & $\begin{array}{l}21.42 \pm 1.08 \\
(20.90-21.95)\end{array}$ & 0.62 & $\begin{array}{l}21.54 \pm 0.56 \\
(21.31-21.777)\end{array}$ & 0.94 \\
\hline A2 length [mm] & $\begin{array}{l}1.78 \pm 0.46 \\
(1.59-1.98)\end{array}$ & $\begin{array}{l}1.61 \pm 0.58 \\
(1.35-1.87)\end{array}$ & 0.27 & $\begin{array}{l}1.62 \pm 0.56 \\
(1.35-1.89)\end{array}$ & 0.29 & $\begin{array}{l}1.63 \pm 0.42 \\
(1.45-1.80)\end{array}$ & 0.22 \\
\hline A2 velocity $[\mathrm{m} / \mathrm{s}]$ & $\begin{array}{l}-0.39 \pm 0.09 \\
(-0.43 \text { to } \\
-0.35)\end{array}$ & $\begin{array}{l}-0.47 \pm 0.13 \\
(-0.53 \text { to } \\
-0.41)\end{array}$ & $0.02^{*}$ & $\begin{array}{l}-0.39 \pm 0.09 \\
(-0.43 \text { to } \\
-0.35)\end{array}$ & 0.91 & $\begin{array}{l}-0.42 \pm 0.12 \\
(-0.47 \text { to } \\
-0.37)\end{array}$ & 0.30 \\
\hline HC Time [ms] & $\begin{array}{l}16.73 \pm 0.39 \\
(16.57-16.89)\end{array}$ & $\begin{array}{l}16.30 \pm 0.63 \\
(16.02-16.58)\end{array}$ & $<0.01^{*}$ & $\begin{array}{l}16.52 \pm 0.48 \\
(16.29-16.75)\end{array}$ & 0.12 & $\begin{array}{l}16.65 \pm 0.42 \\
(16.47-16.82)\end{array}$ & 0.47 \\
\hline Peak dist. [mm] & $\begin{array}{l}3.77 \pm 1.18 \\
(3.28-4.26)\end{array}$ & $\begin{array}{l}4.11 \pm 0.26 \\
(3.55-4.67)\end{array}$ & 0.34 & $\begin{array}{l}4.01 \pm 1.21 \\
(3.43-4.59)\end{array}$ & 0.51 & $\begin{array}{l}3.47 \pm 1.21 \\
(2.97-3.98)\end{array}$ & 0.39 \\
\hline Radius [mm] & $\begin{array}{l}7.00 \pm 1.31 \\
(6.46-7.54)\end{array}$ & $\begin{array}{l}6.41 \pm 1.30 \\
(5.83-6.99)\end{array}$ & 0.12 & $\begin{array}{l}6.60 \pm 0.84 \\
(6.20-7.01)\end{array}$ & 0.25 & $\begin{array}{l}6.67 \pm 0.83 \\
(6.33-7.02)\end{array}$ & 0.29 \\
\hline
\end{tabular}

Parameters are described in detail at Table 1. All data in mean \pm SD $(95 \% \mathrm{CI})$. SD, standard deviation; $95 \% \mathrm{CI}$, $95 \%$ confidence interval for the mean.

Significant $p$ value compared to preoperative data.

showed a significant correlation with the magnitude of the correction (Table 3). Correlations between changes in biomechanical parameters and corneal thinning were as follows: In the case of LASIK, changes of IOP, maximum deformation amplitude, A1 time, A2 length, A2 velocity and radius values showed significant correlations with the corneal thinning. In the case of PRK, changes in A2 length and radius values showed a significant correlation with the corneal thinning (Table 4).

\section{Discussion}

The cornea exhibits both elastic and viscoelastic properties. Until recently, the only device that could characterize the biomechanics of the cornea in vivo was the ORA. This device uses a precise, metered air impulse to impress the cornea. After the air impulse, the cornea takes a concave shape and due to its natural flexibility and the intraocular pressure, returns to its original shape after a short time. We can obtain conclusions about the properties and

Table 3

Correlations between the magnitude of correction and changes in biomechanical parameters after LASIK and PRK measured by CorVis ST.

\begin{tabular}{llcccc}
\hline & \multicolumn{2}{l}{ LASIK } & & \multicolumn{2}{l}{ PRK } \\
\cline { 2 - 3 } \cline { 5 - 6 } & $r$ & & & $r$ & $p$ \\
\hline IOP [mmHg] & 0.48 & $<0.001^{*}$ & & 0.14 & 0.49 \\
Pachy [ $\mu \mathrm{m}]$ & 0.71 & $<0.001^{*}$ & & 0.62 & $<0.001^{*}$ \\
Def. amp. max [mm] & 0.06 & 0.65 & & 0.14 & 0.48 \\
A1 time [ms] & 0.46 & $<0.001^{*}$ & & 0.09 & 0.66 \\
A1 length [mm] & 0.14 & 0.31 & & 0.01 & 0.97 \\
A1 velocity [m/s] & 0.33 & $0.01^{*}$ & & 0.22 & 0.28 \\
A2 time [ms] & 0.06 & 0.67 & & 0.04 & 0.85 \\
A2 length [mm] & 0.36 & $<0.01^{*}$ & & 0.32 & 0.12 \\
A2 velocity [m/s] & 0.18 & 0.17 & & -0.04 & 0.84 \\
HC Time [ms] & 0.19 & 0.14 & & 0.08 & 0.69 \\
Peak dist. [mm] & 0.13 & 0.31 & & -0.13 & 0.51 \\
Radius [mm] & 0.53 & $<0.001^{*}$ & 0.43 & $0.03^{*}$ \\
\hline
\end{tabular}

Parameters are described in detail at Table 1. $r$, Spearman correlation of rho; $p$, level of significance.

* P value below 0.05 was considered statistically significant. data of ocular biomechanics from the parameters of this deformation. Biomechanical measurements are applied in the diagnosis of keratoconus [10,11], the effect studies of refractive surgeries [4-6], the evaluation of corneal collagen cross-linking $[5,7,8]$ and also in the diagnosis of glaucoma $[12,13]$.

Recently, a new device has been introduced which measures new ocular biomechanical properties. Using an air impulse, CorVis ST measures corneal thickness, intraocular pressure and ten specific biomechanical parameters. Although CorVis ST analyzes corneal deformations due to air puff applanation as well, parameters obtained by this device and ORA cannot be compared with each other. Our aim was to evaluate these specific CorVis ST parameters in patients waiting for refractive surgery and to compare pre- and one-month postoperative data after the LASIK and PRK procedures.

We can define and measure several parameters using CorVis ST: the highest concavity, the time from the air-impulse until the highest concavity is reached, the time from air-pulse starting until the first and second applanation, the length of the applanation at the first and second applanation, the maximum speed of the cornea

Table 4

Correlations between changes in biomechanical parameters and corneal thinning after LASIK and PRK measured by CorVis ST.

\begin{tabular}{|c|c|c|c|c|}
\hline & \multicolumn{2}{|l|}{ LASIK } & \multicolumn{2}{|l|}{ PRK } \\
\hline & $r$ & $p$ & $r$ & $p$ \\
\hline IOP [mmHg] & 0.55 & $<0.001^{*}$ & 0.26 & 0.21 \\
\hline Def. amp. max [mm] & -0.32 & $0.02^{*}$ & -0.07 & 0.75 \\
\hline A1 time [ms] & 0.44 & $<0.001^{*}$ & 0.26 & 0.20 \\
\hline A1 length [mm] & -0.06 & 0.65 & -0.12 & 0.58 \\
\hline A1 velocity $[\mathrm{m} / \mathrm{s}]$ & 0.08 & 0.57 & 0.06 & 0.76 \\
\hline A2 time [ms] & -0.08 & 0.56 & 0.07 & 0.73 \\
\hline $\mathrm{A} 2$ length [mm] & 0.33 & $0.02^{*}$ & 0.44 & $0.02^{*}$ \\
\hline A2 velocity $[\mathrm{m} / \mathrm{s}]$ & 0.40 & $0.004^{*}$ & -0.05 & 0.82 \\
\hline HC Time [ms] & -0.06 & 0.69 & 0.16 & 0.45 \\
\hline Peak dist. [mm] & 0.02 & 0.85 & 0.01 & 0.94 \\
\hline Radius [mm] & 0.53 & $<0.001^{*}$ & 0.77 & $<0.001^{*}$ \\
\hline
\end{tabular}

Parameters are described in detail at Table 1. $r$, Spearman correlation of rho; $p$, level of significance.

* $P$ value below 0.05 was considered statistically significant. 
during first and second applanation, the distance of the two corneal apexes at the highest concavity and a radius value that indicates central concave curvature radius at the highest concavity. According to the literature, the repeatability and reproducibility data were poor for most of the CorVis ST parameters except for intraocular pressure, pachymetric data, deformation amplitude and first applanation time [14,15], although second applanation time, highest concavity time, and radius data had low coefficient of variation values [15]. In our examinations, all measurements were performed by the same investigator to eliminate the possible interobserver variability.

Hypothetically, changes in these specific biomechanical parameters can be different regarding the diagnostic group (e.g. glaucoma, keratoconus and postrefractive eyes). A significant change in the biomechanical properties of the cornea is found after PRK, LASIK and epi-LASIK, measured with ORA [4-6,9,16-22]. The decrease in the biomechanical values was significantly larger after LASIK than after PRK, three months postoperatively, with the same preoperative data [20]. According to our measurements with CorVis ST, we can also conclude that one month post-PRK there was a non-significant difference compared to the preoperative value. However, one month after LASIK, two of the device-specific parameters showed significant changes compared to the preoperative data. PRK biomechanically seems to be a less invasive procedure than LASIK [20] as our results suggest, too. This biomechanical weakening could be the reason for corneal ectasia after refractive surgery $[23,24]$.

After corneal refractive surgery, a significant correlation was observed between the amount of correction and changes in biomechanical properties, measured with ORA $[16,18,20]$. These correlations are mostly seen in cases of LASIK in our examinations; these examinations were performed by a new device using highspeed Scheimpflug imaging. In the case of PRK, only changes in the radius value showed significant correlation with the amount of refractive correction, although the preoperative value of radius data was also different in our two intervention groups. Moreover, we can observe significant correlations between the biomechanical parameters and corneal thinning mostly in eyes after LASIK surgery.

A limitation of our study was that we did not separate myopic and hyperopic groups, considering the relatively small number of refractive patients in our preliminary observations.

In conclusion, CorVis ST is an easy-to-use device for assessing ocular biomechanical properties after different types of refractive surgeries. Our preliminary, early results, the first in the literature, showed that some CorVis ST parameters changed after LASIK and PRK, but most of these parameters remain unchanged one month after LASIK and PRK compared to preoperative data. PRK seems to be a less invasive procedure biomechanically than LASIK, as examined by a CorVis ST device. The CorVis ST has the potential for further biomechanical examinations of these two different surgical interventions.

\section{Conflict of interest statement}

None declared.

\section{References}

[1] Soergel F, Jean B, Seiler T, Bende T, Mücke S, Pechhold W, et al. Dynamic mechanical spectroscopy of the cornea for measurement of its viscoelastic properties in vitro. Ger J Ophthalmol 1995;4:151-6.

[2] Kynigopoulos M, Schlote T, Kotecha A, Tzamalis A, Pajic B, Haefliger I, Repeatability of intraocular pressure and corneal biomechanical properties measurements by the ocular response analyser. Klin Monbl Augenheilkd 2008;225:357-60.

[3] Moreno-Montanes J, Maldonado MJ, Garcia N, Mendiluce L, Garcia-Gomez PJ, Segui-Gomez M. Reproducibility and clinical relevance of the ocular response analyzer in nonoperated eyes: corneal biomechanical and tonometric implications. Invest Ophthalmol Vis Sci 2008;49:968-74.

[4] Pepose JS, Feigenbaum SK, Qazi MA, Sanderson JP, Roberts CJ. Changes in corneal biomechanics and intraocular pressure following LASIK using static, dynamic, and noncontact tonometry. Am J Ophthalmol 2007;143: $39-47$.

[5] Spoerl E, Terai N, Haustein M, Bohm AG, Raiskup-Wolf F, Pillunat LE. Biomechanical condition of the cornea as a new indicator for pathological and structural changes. Ophthalmologe 2009;106:512-20.

[6] Chen S, Chen D, Wang J, Lu F, Wang Q, Qu J. Changes in ocular response analyzer parameters after LASIK. J Refract Surg 2010;26:279-88.

[7] Greenstein SA, Fry KL, Hersh PS. In vivo biomechanical changes after corneal collagen cross-linking for keratoconus and corneal ectasia: 1 -year analysis of a randomized, controlled, clinical trial. Cornea 2012;31:21-5.

[8] Spoerl E, Terai N, Scholz F, Raiskup F, Pillunat LE. Detection of biomechanical changes after corneal cross-linking using Ocular Response Analyzer software. J Refract Surg 2011;27:452-7.

[9] Luce DA. Determining in vivo biomechanical properties of the cornea with an ocular response analyzer. J Cataract Refract Surg 2005;31:156-62.

[10] Wolffsohn JS, Safeen S, Shah S, Laiquzzaman M. Changes of corneal biomechanics with keratoconus. Cornea 2012;31:849-54.

[11] Galletti JG, Pförtner T, Bonthoux FF. Improved keratoconus detection by ocular response analyzer testing after consideration of corneal thickness as a confounding factor. J Refract Surg 2012;28:202-8.

[12] Detry-Morel M, Jamart J, Pourjavan S. Evaluation of corneal biomechanical properties with the Reichert Ocular Response Analyzer. Eur J Ophthalmol 2011;21:138-48.

[13] Kaushik S, Pandav SS, Banger A, Aggarwal K, Gupta A. Relationship between corneal biomechanical properties, central corneal thickness, and intraocular pressure across the spectrum of glaucoma. Am J Ophthalmol 2012;153: $840-9$.

[14] Hon Y, Lam AK. Corneal deformation measurement using Scheimpflug noncontact tonometry. Optom Vis Sci 2013;90:e1-8.

[15] Nemeth G, Hassan Z, Csutak A, Szalai E, Berta A, Modis Jr L. Repeatability of ocular biomechanical data measurements with a Scheimpflug-based noncontact device on normal corneas. J Refract Surg 2013;29:558-63.

[16] Chen MC, Lee N, Bourla N, Hamilton DR. Corneal biomechanical measurements before and after laser in situ keratomileusis. J Cataract Refract Surg 2008:34:1886-91.

[17] de Medeiros FW, Sinha-Roy A, Alves MR, Wilson SE, Dupps Jr WJ. Differences in the early biomechanical effects of hyperopic and myopic laser in situ keratomileusis. J Cataract Refract Surg 2010;36:947-53.

[18] Ortiz D, Pinero D, Shabayek MH, Arnalich-Montiel F, Alio JL. Corneal biomechanical properties in normal, post-laser in situ keratomileusis, and keratoconic eyes. J Cataract Refract Surg 2007;33:1371-5.

[19] Gatinel D, Chaabouni S, Adam PA, Munck J, Puech M, Hoang-Xuan T. Corneal hysteresis, resistance factor, topography, and pachymetry after corneal lamellar flap. J Refract Surg 2007;23:76-84.

[20] Kamiya K, Shimizu K, Ohmoto F. Comparison of the changes in corneal biomechanical properties after photorefractive keratectomy and laser in situ keratomileusis. Cornea 2009;28:765-9.

[21] Kamiya K, Shimizu K, Ohmoto F. Time course of corneal biomechanical parameters after laser in situ keratomileusis. Ophthalmic Res 2009;42:167-71.

[22] Ryan DS, Coe CD, Howard RS, Edwards JD, Bower KS. Corneal biomechanics following epi-LASIK. J Refract Surg 2011;27:458-64.

[23] Dupps Jr WJ. Biomechanical modeling of corneal ectasia. J Refract Surg 2005;21:186-90.

[24] Guirao A. Theoretical elastic response of the cornea to refractive surgery: risk factors for keratectasia. J Refract Surg 2005;21:176-85. 